\title{
Bir Eğitim ve Araştırma Hastanesinde Dozimetre Taşıyan Sağık Personelinin İyonlaştırıcı Radyasyon Hakkındaki Risk Algısı ve Bilgi Düzeyinin Belirlenmesi
}

\section{Determination of Risk Perception and Knowledge Level of Ionizing Radiation of Health Personnel Who Carry The Dosimeter in A Training and Research Hospital}

\author{
Yasin UZUNTARLA $^{\mathrm{a}}$ Fatih DOĞAN ${ }^{\mathrm{b}}$
}

ÖZ Amaç: Bu çalışma ile bir eğitim ve araştırmada hastanesinde görev yapmakta olup dozimetre taşıyan sağlık personelinin iyonlaştırıcı radyasyon hakkındaki risk algısı ve bilgi düzeyinin belirlenmesi amaçlanmıştır. Gereç ve Yöntem: Tanımlayıcı nitelikteki bu çalışma, Ankara ilinde faaliyet gösteren 1200 yataklı bir eğitim ve araştırma hastanesinde 15 Mart -15 Haziran 2017 tarihleri arasında gerçekleştirilmiştir. Veri toplama aracı olarak anket yöntemi kullanılmıştır. Verilerin toplanmasında Manavgat (2011) tarafindan geliştirilen "Mesleksel İyonlaştırıcı Radyasyon Risk Algısı Anketi'nden yararlanılmıştır. Örneklem seçilmeyip evrenin tamamına ulaşılması hedeflenmiş ve \%72,1'ine ( $\mathrm{n}=202)$ ulaşılmıştır. Verilerin analizinde SPSS 21.0 paket programı kullanılmıştır. Bulgular: Katılımcıların iyonlaştırıcı radyasyon hakkındaki bilgi düzeyleri puan ortalaması 7,48 $\pm 1,36$, risk algısı puan ortalaması ise $8,98 \pm 1,73$ bulunmuştur. Katılımcıların \%71,3'ünün kişisel koruyucu önlemlerden gonad koruyucuyu, \%67,8'inin gözlüğü hiçbir zaman kullanmadığı, \%30,7'sinin maskeyi bazen kullandığı, \%41,1'inin kurşun önlüğü her zaman kullandığı görülmektedir. Sonuç: Araştırmaya katılan personelin mesleksel iyonlaştırıcı risk algısının yüksek ve bu konudaki bilgi düzeyinin yeterli olduğu bulunmuştur. Radyasyon risk algısı çalışılan birime göre değişmekteyken, bilgi düzeyi mesleki unvana göre değişmektedir. Kişisel koruyucu önlemlerin önemi vurgulanmalı ve tamamının kullanılmasına dair kontrol mekanizması oluşturulmalıdır. Teknisyen/teknikerler başta olmak üzere personelin radyasyon, mesleki tehlike ve riskler konusundaki eğitimleri güncel tutulmalıdır.

Anahtar kelimeler: Bilgi düzeyi, dozimetre, iyonlaştırıcı radyasyon, risk algısı.

ABSTRACT Objective: With this study, it is aimed to determine the risk perception and knowledge level of ionizing radiation of health personnel have dosimeters in a training and research hospital. Material and Methods: This descriptive study was conducted at 1200-beds training and research hospital in Ankara between March 15 and June 15, 2017. Survey method was used as data collection tool. The data were collected with the "Occupational Ionizing Radiation Risk Perception Questionnaire" developed by Manavgat (2011). It was aimed to reach the whole universe but we reached to $72,1 \%(\mathrm{n}=202)$. SPSS 21.0 package program was used to analyse of the data. Results: Participants' knowledge level about ionizing radiation score was 7,48 $\pm 1,36$ (mean) and risk perception score was $8,98 \pm 1,73$ (mean). $71.3 \%$ of the participants never use gonad protectors and $67.8 \%$ of them never use glasses, $30.7 \%$ use masks sometimes, $41.1 \%$ always use lead shielding as personal protective measures. Conclusions: It was found that the personnel who participated in the research had high occupational ionisomer risk perception and sufficient knowledge level in this area. While the radiation risk perception varies according to the unit, the level of knowledge varies according to the professional title. The importance of personal protective measures should be emphasized and the control mechanism must be established about use of whole personal protective measures. Training of personnel, especially technicians should be kept up to date about radiation, occupational hazards and risks.

Keywords: Dosimeter, ionizing radiation, level of knowledge, risk perception

Geliş Tarihi/Received: 23-02-2018 Kabul Tarihi/Accepted:15-11-2018

a Doç. Dr., Gülhane Eğitim ve Araştırma Hastanesi, e-posta:yasinuzuntarla@ gmail.com, ORCID: 0000-0002-5021-3763

bYük.Lisans Öğr., Numune Eğitim ve Araştırma Hastanesi,e-posta: mrsh_11_11@ outlook.com, ORCID: 0000-0002-6389-4289

Sorumlu Yazar /Correspondence: Doç. Dr. Gülhane Eğitim ve Araştırma Hastanesi, e-posta:yasinuzuntarla@gmail.com

*7. Uluslararası Sağlikta Performans ve Kalite Kongresi'nde poster bildiri olarak sunulmuştur. Antalya, 10-13 Ocak 2018.

Atıf: Uzuntarla Y, Doğan F. Bir eğitim ve araştırma hastanesinde dozimetre taşıyan sağlık personelinin iyonlaştırıcı radyasyon hakkındaki risk algısı ve bilgi düzeyinin belirlenmesi. Sağlık Bilimleri ve Meslekleri Dergisi 2019;6(1): 34-41

Citation: Uzuntarla Y, Doğan F. Determination of risk perception and knowledge level of 1onizing radiation of health personnel who carry the dosimeter in a training and research hospital. Journal of Health Science and Profession 2019;6(1): 34-41 


\section{Giriş}

Hastaneler; muayene, teşhis, tedavi ve rehabilitasyon hizmetlerinin sunulduğu, sağl1k sisteminin temelini oluşturan kompleks kurumlardır (1). Sağlık hizmetlerinin sunumu esnasında sağlı personeli birçok riskle karşı karşıya kalmaktadır ve bu doğrultuda hastaneler İş Sağllğı ve Güvenliği kapsamında çok tehlikeli grupta yer almaktadır (2). Bu risklerden birisi de iyonlaştırıcı radyasyona maruziyettir. Radyasyon, ortamda yol alan enerji olarak tanımlanmakta ve iyonize olup olmamasina göre insan vücudunda oluşturduğu etki değişmektedir (3). İyonlaştırıcı olmayan radyasyon düşük enerjiye sahiptir ve cep telefonu, televizyon, uydu, radyo, enerji hatlar1, fotokopi makinesi, mikro dalga firın gibi cihazlar tarafından yayılmaktadır. İyonlaştırıcı radyasyon ise yüksek enerjiye sahip olup çarptığı madde de iyonlar (yüklü parçacıklar) oluşturabilmektedir ve daha tehlikelidir (4). Alfa, beta, gama ve x-ray olmak üzere dört ana çeşidi vardır (5). İyonlaştırıcı radyasyonun tıp, endüstri, tarım alanlarında ve araştırmalarda kullanımı yaygındır (6). Tip alanında ilk olarak 1896 yılında tanı ve tedavi amaçlı kullanılmış ve baryumlu kontrast ise 1920'lerde kullanılmaya başlanmıştır (7). Hastanelerde sunulan hizmetin gereği olarak tanı ve tedavi hizmetlerinde iyonlaştırıcı radyasyona yol açan; röntgen ışınları ve radyoaktif maddeleri barındıran (tomografi ve $\mathrm{x}^{-}$ray cihazlar1, sterilizatör ve ultraviyole lambalar gibi) tıbbi cihazlar ağırlıklı olarak kullanılmaktadır (4,8-10). İyonize radyasyon kullanılan doza ve maruziyet sıklığına göre deterministik (ölüm, cilt yanığı, katarakt, kısırlık, vb.) ya da skostatik (kanser, genetik değişiklik) birçok istenmeyen sonuca yol açabilmektedir (11-13). İyonize radyasyona maruz kalan sağlık personellerinde gerekli önlemler alınmazsa doku hasarının onarılamamas1 ve dozla birlikte hasarın da artmasına bağlı olarak yıllar sonra bile deterministik ya da skostatik etkiler görülebilmektedir (14).

Risk algısı, tehlikeli bir olayın özelliği, gerçekleşme ihtimali ve şiddetinin bireyi hangi düzeyde ilgilendirdiği ile ilgili öznel bir değerlendirmedir (15). Kişinin eğitim durumuna, çevresine ve tecrübesine göre farkl1lık göstermektedir. Risk algısı çalışmaları ile tehlikenin ortaya çıkma olasılığı ve vereceği zararın ortaya konularak farkındalık oluşturulması amaçlanmaktadır (16). Dünya genelinde her yıl 32 milyon nükleer tıp tetkiki, 7 milyon radyoterapi uygulaması ve 2 milyar radyoloji tetkiki uygulandığı değerlendirildiğinde (17), iyonlaştırıcı radyasyonun bulunduğu birimlerde görev yapan sağlık personelinin risk algısının yüksek olması ve gerekli eğitimleri ve önlemleri alması beklenmektedir.

\section{Gereç ve Yöntem}

\section{Araştırmanın Amacı}

$\mathrm{Bu}$ çalışma ile bir eğitim ve araştırmada hastanesinde görev yapmakta olup dozimetre taşıyan sağlık personelinin iyonlaştırıcı radyasyon hakkındaki risk algisı ve bilgi düzeyinin belirlenmesi amaçlanmıştır.

\section{Araştırmanın Evren ve Örneklemi}

Tanımlayıcı nitelikteki bu çalışma, Ankara ilinde faaliyet gösteren 1200 yataklı bir eğitim ve araştırma hastanesinde 15 Mart -15 Haziran 2017 tarihleri arasında gerçekleştirilmiştir. Çalışmanın evrenini dozimetre taşıyan sağlık personelleri oluşturmaktadır. Örneklem seçilmeyip evrenin tamamına $(\mathrm{N}=280)$ ulaşılması hedeflenmiş olup, izin/kurum dişı geçici görevlendirme $(n=33)$ ve ankete katılmak istememe $(\mathrm{n}=45)$ gibi nedenlerden dolayı evrenin \%72,1'ine $(n=202)$ ulaşılmıştır.

\section{Veri toplama Araçları}

Veri toplama aracı olarak anket yöntemi kullanılmıştır. Literatürde radyasyon risk algısına yönelik geliştirilen ölçekler olmakla birlikte $(18,19)$, mesleki iyonlaştırıcı radyasyon risk algısına yönelik Manavgat tarafindan 2011 yılında geliştirilen "Mesleksel İyonlaştırıcı Radyasyon Risk Algisı Anketi" bulunmaktadır $(16,20)$. Bu anket daha sonra Öztürk ve arkadaşlarının çalışmasında kullanılmış olup (21), araştırmamızda da bu anketten yararlanılmıştır. Anket formunda katılımcıların sosyodemografik özelliklerini, çalışma ortamı ve koşullarını, risk algısını, konuyla ilgili davranışlarını içeren 21 soru ile iyonlaştırıcı radyasyon hakkındaki bilgi düzeylerini belirlemeye yönelik 10 soru olmak üzere toplam 31 soru yer almaktadir.

Mesleksel iyonlaştırıcı radyasyon risk algısı 0-10 arasında (0: Hiç risk yok, 5: Orta 
düzeyde risk, 10: Çok yüksek risk) değerlendirilmiştir.

\section{Verilerin Analizi}

Verilerin analizinde SPSS 21.0 paket programı kullanılmıştır. Bağımsız gruplarda $\mathrm{t}$ testi, tek yönlü varyans analizi, post hoc tukey testi testleri uygulanmıştır. Anket formunda farklı türde (açık uçlu, evet-hayır, doğru yanlış) soruların yer alması sebebiyle güvenilirliği değerlendirilememiştir.

\section{Araştırmanın Etik Yönü}

Araştırma, Ankara İli 1. Bölge Kamu Hastaneler Birliği Genel Sekreterliği Bilimsel Araştırmalar Değerlendirme Etik Komisyonu (2017/1213 sayılı karar) tarafindan uygun bulunarak gerçekleştirilmiştir.

\section{Bulgular}

Katılımcıların sosyodemografik özelliklerine bakıldı ğında yaş ortalamasının 39,68 $\pm 9,09$ (18-62 yıl aralığında) olduğu ve \%44,1'inin 36-45 yaş grubunda, \%55'inin erkek, \%68,8'inin evli, yarısından fazlasinın teknisyen/tekniker, \%64,4'ünün çocuk sahibi olduğu, \%44,6'sının 11-20 y1l aras1 tecrübeye sahip olduğu, \%43,6'sının hemodinami veya diğer birimlerde görev yaptığ 1 \%35,6'sının bu birimdeki çalışma süresinin 6-15 yıl olduğu bulunmuştur. Ayrıca \%78,7'si denetimli alanda çalıştığını, \%64,4'ü günde 7 saat mesai yaptığını, yarısından fazlası iş yükünün son 6 ay içerisinde eskisine oranla arttığını ifade etmiştir (Tablo 1).

Araştırmaya katılanların iyonlaştırıcı radyasyon hakkındaki bilgi düzeylerini belirlemeye yönelik sorulara verdikleri yanıtların puan ortalaması (0-10 aralığında) $7,48 \pm 1,36$ olarak bulunmuştur. Meslek grupları arasında istatistiksel olarak anlamlı farklılık vardır $(\mathrm{p}<0,05)$. İyonlaştırıcı radyasyon ile ilgili sorulan bazı sorulara personelin verdiği yanttlar Tablo 2 'te sunulmuştur. Buna göre $\% 53$, ü iyonlaştırıcı radyasyon ve korunma yolları hakkında bilgi kaynağ 1 olarak mezuniyet öncesi eğitimi göstermiştir. \%59,9’u son iki y1l içerisinde mesleksel tehlike ve risklere yönelik eğitim almadığını, \%82,2'si iyonlaştırıcı radyasyonla çalışanların haklarını bildiğini, \%78,2'si
Tablo 1. Katılımcıların Sosyodemografik Özellikleri

\begin{tabular}{|c|c|c|}
\hline Değişkenler & $\mathrm{n}$ & $\%$ \\
\hline \multicolumn{3}{|l|}{ Yaş $(39,68 \pm 9,09)$} \\
\hline $18-35$ & 66 & 32,7 \\
\hline $36-45$ & 89 & 44,1 \\
\hline $46-62$ & 47 & 23,2 \\
\hline \multicolumn{3}{|l|}{ Cinsiyet } \\
\hline Kadın & 91 & 45,0 \\
\hline Erkek & 111 & 55,0 \\
\hline \multicolumn{3}{|l|}{ Medeni durum } \\
\hline Evli & 139 & 68,8 \\
\hline Bekar/dul/boşanmış & 63 & 31,2 \\
\hline \multicolumn{3}{|l|}{ Çocuk sahibi olma durumu } \\
\hline Hayır & 72 & 35,6 \\
\hline 1 çocuk & 60 & 29,7 \\
\hline 2 çocuk & 57 & 28,2 \\
\hline 3 çocuk & 13 & 6,4 \\
\hline \multicolumn{3}{|l|}{ Meslek } \\
\hline Hekim & 48 & 23,8 \\
\hline Hemşire & 26 & 12,9 \\
\hline Tekniker/Teknisyen & 103 & 51,0 \\
\hline Fizikçi/Biyolog/Kimyager/Diğer & 25 & 12,4 \\
\hline \multicolumn{3}{|l|}{ Meslekte geçen süre $(16,46 \pm 8,37)$} \\
\hline$\leq 10$ & 47 & 23,3 \\
\hline $11-20$ & 90 & 44,6 \\
\hline $21-35$ & 65 & 32,2 \\
\hline \multicolumn{3}{|l|}{ Çalıştı ̆̆ Birim } \\
\hline Tomografi & 67 & 33,2 \\
\hline Girişimsel Radyoloji (DSA) & 24 & 11,9 \\
\hline Konvansiyonel & 23 & 11,4 \\
\hline Hemodinami veya diğer birimler & 88 & 43,6 \\
\hline \multicolumn{3}{|l|}{$\begin{array}{l}\text { Birimdeki çalışma süresi } \\
(10,45 \pm 7,15)\end{array}$} \\
\hline$\leq 5$ & 71 & 35,1 \\
\hline $6-15$ & 78 & 35,6 \\
\hline $16-27$ & 53 & 26,2 \\
\hline \multicolumn{3}{|l|}{ Çalıştığl alan } \\
\hline Denetimli alan & 159 & 78,7 \\
\hline Gözetimli alan & 25 & 12,4 \\
\hline Hiçbiri & 3 & 1,5 \\
\hline Bilmiyorum & 15 & 7,4 \\
\hline \multicolumn{3}{|l|}{ Çalışma saatleri } \\
\hline Günde 7 saat vardiya & 130 & 64,4 \\
\hline Günde 7 saatten fazla mesai & 64 & 31,7 \\
\hline Nöbet (ayda 140 saat) & 8 & 4,0 \\
\hline \multicolumn{3}{|l|}{ 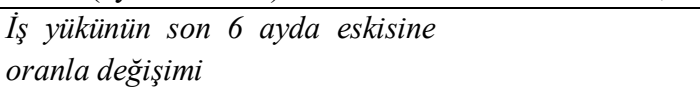 } \\
\hline Eskisiyle aynı & 90 & 44,6 \\
\hline Azald1/hafifledi & 7 & 3,5 \\
\hline Arttı/ağırlaştı & 103 & 51,0 \\
\hline Fikrim yok & 2 & 1,0 \\
\hline
\end{tabular}


Tablo 2. İyonlaştırıcı Radyasyon İle İlgili Bazı Sorulara Verilen Yanıtların Dağılımı

\begin{tabular}{lcc}
\hline & $\mathrm{n}$ & $\%$ \\
\hline $\begin{array}{l}\text { İyonlaştırıcı radyasyon ve } \\
\text { korunma yolları hakkında } \\
\text { bilgilerinizi en çok nereden }\end{array}$ & \\
aldınız? & & \\
\hline $\begin{array}{l}\text { Mezuniyet öncesi eğitimimde } \\
\text { okuldan }\end{array}$ & 107 & 53,0 \\
Çalışmaya başladıktan sonra & 73 & 36,1 \\
hizmet içi eğitimde & & \\
İşarkadaşlarımdan & 19 & 9,4 \\
Medya ve internetten & 3 & 1,5 \\
\hline $\begin{array}{l}\text { Son iki yılda mesleksel tehlike ve } \\
\text { risklere yönelik eğitim aldınız mı? }\end{array}$ & & \\
Hayır & 121 & 59,9 \\
Evet & 81 & 40,1 \\
\hline İyonlaştırıcı radyasyonla & & \\
çalışanların haklarını biliyor & & \\
musunuz? & & \\
Hayır & & \\
Evet & & \\
\hline Hastanenizde “Radyasyon & & \\
Güvenliği Komitesi” olduğunu \\
biliyor musunuz? \\
Hayır
\end{tabular}

hastanede "Radyasyon Güvenliği Komitesi" olduğunu bildiğini, $\% 54,5$ 'i çalışma ortamında etkin olarak çalışan (klima hariç) özel bir havalandırma olduğunu, \%78,7'si iyonlaştırıc1 radyasyon yayan cihazların kalibrasyonu ve kontrolünün düzenli olarak yapıldığını, \%85,6's1 kişisel koruyucuları temin etmekte zorluk yaşamadığını, \%35,6'sı iyonlaştırıcı radyasyonla çalışırken tehlikeli olduğunu bildiği bir davranış1 aşırı iş yükünden dolayı yapmak zorunda kaldığını ifade etmiştir.

Katılımciların \%71,3'ünün gonad koruyucuyu, \%67,8'inin gözlüğü hiçbir zaman kullanmadığı, \%30,7'sinin maskeyi bazen kullandığ1, \%41,1'inin kurşun önlüğü her zaman kullandığı görülmektedir (Tablo 3).

Mesleksel iyonlaştırıcı radyasyon risk algıs1 $0-10$ arasında $(0=$ Hiç risk yok, 5=Orta düzeyde risk, $10=$ Çok yüksek risk) değerlendirilmiş olup, çalışmamızda risk algısı ortalamas1 $8,98 \pm 1,73$ olarak bulunmuștur. Katılımcıların \%67,8'i çok yüksek, \%20,4'ü yüksek, \%11,8'i orta düzeyde risk algısına sahiptir. Düşük risk algısına sahip personel bulunmamıştır.

Çalışmamızda çalışılan birim açısından mesleksel iyonlaştırıcı radyasyon risk algısı ortalamasına bakıldığında gruplar arasında istatistiksel olarak anlamlı fark olduğu ve farkın tomografi ile DSA ve hemodinami/diğer birimler arasında olduğu görülmektedir $(\mathrm{p}<0,001)$. Katılımcıların yaş ve meslekleri başta olmak üzere diğer sosyodemografik özellikleri açısından risk algis1 ortalamalarında istatistiksel olarak anlamlı fark bulunmamıștır (Tablo 4).

Tablo 3. Kișisel Koruyucu Önlemler ve Kullanım Siklığı

\begin{tabular}{lcccccc}
\hline & \multicolumn{2}{c}{$\begin{array}{c}\text { Her } \\
\text { zaman }\end{array}$} & \multicolumn{2}{c}{ Bazen } & \multicolumn{2}{c}{$\begin{array}{c}\text { Hiçbir } \\
\text { zaman }\end{array}$} \\
\cline { 2 - 7 } & $\mathrm{n}$ & $\%$ & $\mathrm{n}$ & $\%$ & $\mathrm{n}$ & $\%$ \\
\hline $\begin{array}{l}\text { Kurşun } \\
\text { önlük }\end{array}$ & 83 & 41,1 & 52 & 25,7 & 67 & 33,2 \\
\hline Gözlük & 17 & 8,4 & 48 & 23,8 & 137 & 67,8 \\
\hline Maske & 34 & 16,8 & 62 & 30,7 & 106 & 52,5 \\
\hline $\begin{array}{l}\text { Tiroid } \\
\text { koruyucu }\end{array}$ & 69 & 34,2 & 34 & 16,8 & 99 & 49,0 \\
\hline Eldiven & 52 & 25,7 & 32 & 15,8 & 118 & 58,4 \\
\hline $\begin{array}{l}\text { Gonad } \\
\text { Koruyucu }\end{array}$ & 35 & 17,3 & 23 & 11,4 & 144 & 71,3 \\
\hline
\end{tabular}


Tablo 4. Risk algısı ortalaması ile bazı sosyodemografik özelliklerin ilişkisi

\begin{tabular}{|c|c|c|c|}
\hline & \multicolumn{3}{|c|}{ Risk Algis1 } \\
\hline & & Ort \pm SS. & Test istatistiği \\
\hline \multirow{3}{*}{ Yaş } & $18-35$ & $9,18 \pm 1,48$ & $\mathrm{p}=0,270$ \\
\hline & $36-45$ & $8,76 \pm 1,90$ & $\mathrm{~F}=1,314 *$ \\
\hline & $46-62$ & $9,12 \pm 1,68$ & \\
\hline \multirow{4}{*}{ Meslek } & Hekim & $8,75 \pm 2,08$ & $\mathrm{p}=0,680$ \\
\hline & Hemşire & $9,23 \pm 1,47$ & $\mathrm{~F}=0,500 *$ \\
\hline & Tekniker/Teknisyen & $9,03 \pm 1,67$ & \\
\hline & Fizikçi/Biyolog/Kimyager/Diğer & $8,96 \pm 1,48$ & \\
\hline \multirow{4}{*}{ Çalıştığı birim } & Tomografi $^{1}$ & $9,74 \pm 0,92$ & $\mathrm{P}<0,001^{\mathrm{a}, \mathrm{b}}$ \\
\hline & $\mathrm{DSA}^{2}$ & $7,91 \pm 2,30$ & $\mathrm{~F}=9,527 *$ \\
\hline & Konvansiyonel $^{3}$ & $9,13 \pm 1,48$ & \\
\hline & Hemodinami veya diğer birimler ${ }^{4}$ & $8,65 \pm 1,85$ & \\
\hline
\end{tabular}

Ort: Risk algısı ortalaması, Ss: Standart sapma, a:1-2 arasında, b: 1-4 arasında, *Tek yönlü varyans analizi, ** Post Hoc Tukey testi

\section{Tartışma}

$\mathrm{Bu}$ çalışma ile bir eğitim ve araştırmada hastanesinde görev yapmakta olup dozimetre taşıyan sağlık personelinin iyonlaştırıcı radyasyon hakkındaki risk algisı ve bilgi düzeyinin belirlenmesi amaçlanmıştır. Araştırmamızda dozimetre taşıyan sağlık personelinin mesleksel iyonlaştırıcı radyasyon risk algis1 ortalamas1 (0-10 puan aralığında) $8,98 \pm 1,73$ olarak bulunmuştur. Risk algis1 ortalamas1 Manavgat ve Mandiracıoğlu'nun çalışmasında 7,05 $\pm 2,30$, Öztürk ve arkadaşlarının çalışmasında 7,51 $\pm 2,09$ olarak bulunmuştur $(16,21)$. Araştırma sonuçlarının benzerlik gösterdiği ve personelin risk algısının yüksek olduğu değerlendirilmektedir. Araştırmanın uygulandığ1 hastanede, 1996 yılında Uçar tarafindan doktorlarla yapılan çalışmada katılımcıların \%30,8'inin yüksek, \%55,7'sinin orta, \%13,5'inin düşük radyasyon risk algısına sahip olduğu bulunmuştur (22). Çalışmamızda ise \%67,8'inin çok yüksek, \%20,4'ünün yüksek, $\% 11,8$ 'inin orta düzeyde risk algısına sahip olduğu bulunurken düşük risk algısına sahip personel bulunmamaktadır. Aradan geçen yaklaşık 20 yılda personelin risk algısının oldukça yükseldiği görülmektedir. Bunda çalışma yoğunluğu ve işlem sayısındaki artışın yanı sıra personelin eğitim ve bilinç düzeyinin yükselmesinin de etkili olabileceği değerlendirilmektedir.

Çalışmamızda katılımcıların yaşlarına göre risk algisı ortalamasında anlamlı farklılık bulunmamış olup, önceki çalışmalarla benzerlik göstermektedir $(16,23,24)$. Seong ve arkadaşları tarafından Kore'de gerçekleştirilen çalışmada ise 40-49 yaş aralığında olanlar ile 11 yıl üzerinde deneyime sahip olanların risk algısının daha düşük olduğu bulunmuştur (18).Literatürde riskin uzun süre devam etmesinin riske aşinalık oluşturduğu ve dolayısıyla yaşın ilerlemesiyle birlikte risk algısının düştüğüne yönelik araştırma sonuçları da bulunmaktadır (25).

Araştırmamızda mesleki unvanlara göre de risk algis1 ortalamasında anlamlı farklılık bulunmazken, Öztürk ve arkadaşlarının çalışmasında hekimlerin diğer çalışanlara göre, Erkan ve Zencir'in çalışmasında ise teknisyenlerin hemşirelere göre daha düşük risk algısına sahip oldukları bulunmuştur $(21,26)$. Cooper, risk algısının aynı birimde çalışan değişik unvan gruplarında farklılık gösterebileceğini ifade etmektedir (27). Ayrica Perko tarafindan (28), işleri gereği düzenli olarak radyasyona maruz kalan kişiler ile risk altındaki insanlar arasındaki 
radyasyon risk algılarındaki farkl11ıkların belirlenmesine yönelik gerçekleştirilen çalışmada, uzmanların halka göre risk algısının daha düşük olduğu bulunmuştur. Ibanez ve arkadaşları tarafindan Filipinli öğrencilerle gerçekleştirilen çalışmada da sağlık alanında öğrenim gören öğrencilerin diğerlerine göre radyasyon risk algısı daha düşüktür (19). Bilgi seviyesinin yükselmesinin, risk algısının azalmasında etkili olduğu düşünülmektedir. Çalışılan birim açısından risk algısı ortalamalarına bakıldığında tomografide çalışanların, DSA ile hemodinami veya diğer birimlerde çalışanlara göre daha yüksek risk algısına sahip oldukları bulunmuştur. Manavgat ve Mandıracıoğlu'nun çalışmasında DSA'da, Öztürk ve arkadaşları'nın çalışmasında ise kardiyolojide çalışanların en yüksek risk algısına sahip oldukları bulunmuştur $(16,21)$.

Katılımcıların iyonlaştırıcı radyasyon hakkındaki bilgi düzeyleri puan ortalaması (0-10 aralığında) 7,48土1,36 olarak bulunmuşken, Manavgat ve Mandıracıoğlu'nun çalışmasında $5,99 \pm 2,07$, Öztürk ve arkadaşlarının çalışmasında ise $6,59 \pm 2,18$ olarak bulunmuştur $(16,21)$. Ayrıca meslek grupları açısından bakıldığında hekimler ile tekniker/teknisyenler arasında fark olduğu ve hekimlerin bilgi düzeyinin beklenildiği üzere anlamlı olarak yüksek olduğu bulunmuştur. $\mathrm{Bu}$ sonuç Ataç ve arkadaşlarının çalışmasıyla benzerlik taşımaktadır (29). Özel ve arkadaşlarının çalışmasında ise asistan ve uzman hekimlerin bilgi düzeyleri arasında anlamlı fark olmadığ 1 bulunmuştur (30).

Kişisel koruyucu önlemler ve kullanım sıklığı açısından bakıldığında sırasıyla gonad koruyucuyu ve gözlüğün büyük oranda kullanılmadığı, kurşun önlüğün ise en s1k kullanılan koruyucu önlem olduğu bulunmuştur. Öztürk ve arkadaşları ile Kaya'nın çalışmasında gözlük, Vural ve arkadaşlarının çalışmasında tiroid koruyucunun büyük oranda kullanılmadığ bulunmuştur (21,31,32). Sonuçlar literatürle benzerlik göstermektedir. Kang ve arkadaşlarının çalışmasında sağlık personellerinin kişisel koruyucu ekipmanları zaman alıcı, hantal ve etkili koruma sağlamadığ 1 düşüncesiyle yeterince kullanmadığ 1 bulunmuştur (33).

$\mathrm{Bu}$ çalışmanın katılımcılara ulaşım kolaylığı açısından sadece araştırmacıların görev yaptığı hastanede gerçekleştirilmesi araştırma- nının sınırlılığını oluşturmaktadır. Bu nedenle çalışma sonuçları evrene genellenemez.

\section{Sonuç ve Öneriler}

Araştırmaya katılan personelin mesleksel iyonlaştırıcı risk algısının yüksek ve bu konudaki bilgi düzeyinin yeterli olduğu bulunmuştur. Radyasyon risk algısı çalışılan birime, bilgi düzeyi ise mesleki unvana göre değişmektedir. Kişisel koruyucu önlemlerin önemi vurgulanmalı ve tamaminın kullanılmasina dair kontrol mekanizması oluşturulmalıdır. Teknisyen/ teknikerler başta olmak üzere personelin radyasyon, mesleki tehlike ve riskler konusundaki eğitimleri güncel tutulmalıdır. İyonlaştırıcı radyasyon risk algısı ve bilgi düzeyi ile ilgili gelecekteki araştırmaların, özel hastaneleri de kapsayacak şekilde çok merkezli yürütülerek kıyaslama yapılması ve sağlık çalışanlarının kişilik özellikleri, sürekli kaygı düzeyi gibi değiş̧kenlerle olan ilişkisinin incelenmesi önerilmektedir.

\section{Kaynaklar}

1. Terekli G, Özkan O, Bayın G. Çevre dostu hastaneler: hastaneden yeşil hastaneye. Ankara Sağlı Hizmetleri Dergisi 2013;12(2):37-54.

2. İş sağlı̆̆ ve güvenliğine ilişkin işyeri tehlike sınıfları tebliğinde değişiklik yapılmasına dair tebliğinde değişiklik yapılmasına dair tebliğ Çalışma ve Sosyal Güvenlik Bakanlığı, http://www.resmigazete.gov.tr/eskiler/2017/0 2/20170227M1-1.htm (ET: 01.09.2017)

3. Yaren H, Karayılanoğlu T. Radyasyon ve insan sağlığ 1 üzerine etkileri. TSK Koruyucu Hekimlik Bülteni 2005;4(4):199-208.

4. Ege Üniversitesi Tip Fakültesi Hastanesi Radyasyon Güvenliği E1 Kitabı. İzmir, 2014.

5. Shapiro J. Radiation protection - a guide for scientists, regulators, and physicians, gamma rays - a major class of uncharged ionizing particles. 4 th ed. Massachusetts: Harvard University Press; 2002.

6. Zakariya NI, Kahn MTE. Benefits and biological effects of ionizing radiation. Sch.Acad. J.Biosci. 2014;2(9):583-91.

7. Ron E. Cancer risks from medical radiation. Health Phys 2003;85(1):47-59.

8. Çelik H, Koyuncu İ, Karakılçık AZ, Gönel A, Musa D. Radyasyonlu ortamlarda çalışan 
insanlarda iyonize ve non-iyonize radyasyonun oksidatif stres ve antikosidan seviye üzerindeki etkileri. Bezmialem Science 2016;3:106-9.

9. Schmid E, Schrader T. Different biological effectiveness of ionising and non-ionising radiations in mammalian cells. Adv Radio Sci 2007; 5: 1-4.

10.Sowa P, Rutkowska-Talipska J, Sulkowska U, Rutkowski K, Rutkowski R. Ionizing and nonionizing electromagnetic radiation in modern medicine. Polish Ann Med 2012; 19: 134-8.

11.Bolus NE. Basic review of radiation biology and terminology. J Nucl Med Technol 2001;29:67-73.

12.Koçyiğit A, Kaya F, Çetin T, Kurban I, Erbaş $\mathrm{T}$, Ergin A, ve ark. Radyolojik tetkikler sırasında maruz kalınan radyasyon hakkında sağlık personelinin bilgi düzeyleri. Pamukkale Tip Dergisi 2014;7(2): 137-142.

13.Frischknecht R, Braunschweig A, Hofstetter P, Suter P. Human health damages due to ionizing radiation in life cycle impact assessment. Environ. Impact Assess. Rev. 2000; 20:159-189.

14. Sanchez AJG, Angosto EAG, Riquelme PAM, Berna AS, Amores DR. Ionizing radiation measurement solution in a hospital environment. Sensors 2018;18:510.

15.Çokluk E, Çokluk S, Şekeroğlu R, Huyut Z. Sağlık hizmetleri sektöründe risk algısı: Hastane Laboratuvar ön çalışması. Türk Klinik Biyokimya Derg 2016;14(2):125-130.

16. Manavgat SK, Mandıracioğlu A. Ege Üniversitesi Tip Fakültesi Hastanesi'nde kişisel dozimetre taşıyan çalışanların mesleksel iyonlaştırıcı radyasyon risk algısı. Mesleki Sağlık ve Güvenlik Dergisi 2012;43:34-43.

17.Internal Commission on Radiological Protection (ICRP). Radiological protection in medicine. ICRP Publication 105, Elseiver Ltd.; 2008.

18. Seong KM, Kwon T, Seo S, Lee D, Park S, Jin YW, et al. Perception of low doze radiation risks among radiation researchers in Korea. PLoS One 2017;12(2):e0171777.

19.Ibanez DD, Manaois RAB, Soledad MD, Bracil KGF. Radiation scare: An analysis of students' perception to risks of ionizing radiation. International Conference on
Advances in Medical and Health Sciences, Thailand, 2016;37-43.

20.Manavgat SK. Ege Üniversitesi Tıp Fakültesi Hastanesi'nde Kişisel Dozimetre Taşıyan Çalışanların Mesleksel İyonlaştırıcı Radyasyon Risk Algısı ve İlişkili Etmenler. Ege Üniversitesi Tıp Fakültesi Halk Sağlı̆̆ Anabilim Dalı Uzmanlık Tezi, İzmir, 2011.

21.Öztürk YE, Türktemiz H, Akdağ T. Dozimetre taşıyan sağlık çalışanlarında iş yükünün iyonlaştırıcı radyasyon risk algısına etkisi. Hacettepe Sağlik İdaresi Dergisi 2017;20(2):143-155.

22.Uçar M. Gata Hastanesinde İyonizan Radyasyon Riski Altında Çalışan Doktorlarda Risk Algilamalarının Belirlenmesi. Genelkurmay Başkanlığı Gülhane Askeri Tıp Akademisi Uzmanlık Tezi, Ankara, 1996.

23.Özkan, Ö. Hastanede çalışan hemşirelerin iş ve çalışma ortamı tehlike ve riskleri ile risk algılarının saptanması. Hacettepe Üniversitesi Sağlık Bilimleri Enstitüsü Halk Sağlığ1 Hemşireliği Doktora Tezi, Ankara, 2005.

24.Öcek Z, Türk Soyer M, Davas Aksan A, Hassoy H, Sakaoğlu Manavgat S. Risk perception of occupational hazards among dental health care workers in a dental hospital in Turkey. International Dental Journal 2008;58: 199-207.

25. Weinstein ND, Nicolich M. Correct and incorrect interpretations of correlations between risk perceptions and risk behaviors. Health Psychol 1993; 12: 235-245.

26. Erkan S, Zencir M. Bir üniversite hastanesinde çalışan hemşire ve teknisyenlerin mesleki risk algısının belirlenmesi. Mesleki Sağlık ve Güvenlik Dergisi 2016;60-61:57-66.

27. Cooper MD. Evidence from safety culture that risk perception is culturally determined. The International Journal of Project \& Business Risk Management 1997; 1(2): 185-202.

28.Perko T. Radiation risk perception: a discrepancy between the experts and the general population. Journal of Environ Radioactiv 2014;133:86-91.

29. Ataç GK, İnal $\mathrm{T}$, Alhan $\mathrm{A}$, Pabuşçu $\mathrm{Y}$. Radyoloji çalışanlarının radyasyondan korunma farkındalığının değerlendirilmesi. Türk Radyoloji Derg 2016;35:52-8.

30. Özel D, Özel BD, Özkan F, Akan D, Özer Ö, Halefoğlu AM. Klinisyen hekimlerin iyonizan 
radyasyon ve radyolojik görüntüleme yöntemleri hakkında bilgi düzeyleri: kesitsel anket çalışması. Okmeydanı Tıp Dergisi 2015, 31(4):189-193.

31.Kaya A. Akdeniz üniversitesi hastanesi merkez laboratuvarı çalışanlarının mesleki biyolojik risk alg1 düzeyleri ve etkileyen faktörler ile biyolojik risk değerlendirme ve risk analizi çalışması. Akdeniz Üniversitesi Tıp Fakültesi Halk Sağlığı Anabilim Dalı Uzmanlık Tezi, Antalya, 2013.

32. Vural F, Fil Ş, Çiftçi S, Dura AA, Yıldırım F, Patan R. Ameliyathanelerde radyasyon güvenliği; çalışan personelin bilgi, tutum ve davranışları. Balıkesir Sağlık Bilimleri Dergisi 2012;1(3): 131-6.

33.Kang J, O'Donnell JM, Colaianne B, Bircher N, Ren D, Smith KJ. Use of personal protective equipment among health care personnel: Results of clinical observations and simulations. Am J Infect Control 2017;45:1723. 